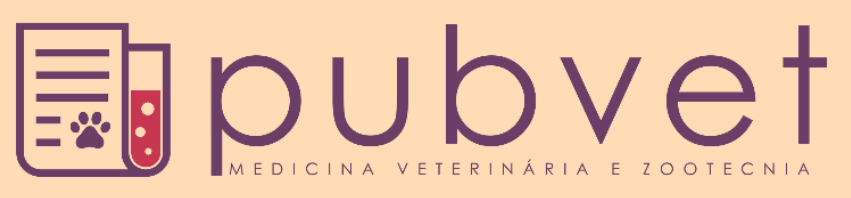

https://doi.org/10.31533/pubvet.v13n12a468.1-6

\title{
Nocardiose cutânea em cães e gatos: Revisão
}

\author{
Adriana Leão de Carvalho Lima Gondim ${ }^{10}$, Adjanna Karla Leite Araujo ${ }^{2} \bullet$ \\ ${ }^{I}$ Médica veterinária graduada pela Universidade Federal Rural de Pernambuco - UFRPE, Pós-graduada em Dermatologia Veterinária de \\ Pequenos Animais pela instituição Qualittas - Universidade Castelo Branco. \\ ${ }^{2}$ Médica veterinária graduada pela Universidade Federal de Campina Grande - Campus de Patos/PB, Pós-graduada em Dermatologia \\ Veterinária de Pequenos Animais pelas instituições Qualittas - Universidade Castelo Branco e Equalis, Especialização em Parasitologia \\ Clínica e Saúde Pública pela UPE, Mestrado em Ciências Veterinárias pela Universidade Estadual do Ceará e pelo Centro de Pesquisa Aggeu \\ Magalhães - FIOCRUZ-PE. \\ *Autor para correspondência, E-mail: adrianalclg@gmail.com
}

Resumo. As dermatopatias representam grande parte dos casos atendidos na clínica médica de pequenos animais. Dentre as afecções cutâneas, as doenças bacterianas estão entre as mais frequentes na prática dermatológica. $\mathrm{O}$ gênero Nocardia consiste em bactérias aeróbicas, gram-positivas, altamente patogênicas para animais e humanos, sendo encontradas normalmente no solo, na água, entre outros locais. Atualmente, a nocardiose tem sido considerada uma doença emergente entre os seres humanos e animais domésticos em todo o mundo. A infecção ocorre através de inalação de aerossóis e contato com o ambiente contaminado ou pela inoculação percutânea do agente através de feridas ou traumas, causando, respectivamente, as formas clínicas respiratória e cutânea (mais comum) da doença. $\mathrm{O}$ objetivo deste trabalho é fazer uma revisão bibliográfica sobre a nocardiose em cães e gatos, alertando o clínico veterinário sobre a ocorrência de tal afecção.

Palavras chave: dermatologia, doenças bacterianas, cão, gato, nocardiose, Nocardia spp.

\section{Cutaneous nocardiosis in dogs and cats: Review}

Abstract. Dermatopathies represent a large part of the cases seen at the small animal medical clinic. Among skin diseases, bacterial diseases are among the most frequent in dermatological practice. The genus Nocardia consists of aerobic, gram-positive, highly pathogenic bacteria for animals and humans, normally found in soil, water, and other places. Currently, nocardiosis has been considered an emerging disease among humans and domestic animals worldwide. Infection occurs through inhalation of aerosols and contact with the contaminated environment or by percutaneous inoculation of the agent through wounds or trauma, causing, respectively, the clinical respiratory and cutaneous (most common) forms of the disease. The aim of this paper is to make a bibliographic review about nocardiosis in dogs and cats, alerting the veterinarian about the occurrence of such condition.

Keywords: dermatology, bacterial diseases, dog, cat, nocardiosis, Nocardia spp.

\section{Nocardiosis cutánea en perros y gatos: Revisíon}

Resumen. Las dermatopatías representan una gran parte de los casos vistos en la clínica médica de pequeños animales. Entre las enfermedades de la piel, las enfermedades bacterianas se encuentran entre las más frecuentes en la práctica dermatológica. El género Nocardia consiste en bacterias aerobias, gram positivas, altamente patógenas para animales y humanos, que normalmente se encuentran en el suelo, el agua y otros lugares. Actualmente, la nocardiosis se ha considerado una enfermedad emergente entre humanos y animales domésticos en todo el mundo. La infección ocurre por inhalación de aerosoles y contacto con el ambiente contaminado o por inoculación percutánea del agente a través 
de heridas o traumatismos, causando, respectivamente, las formas clínicas respiratorias y cutáneas (más común) de la enfermedad. El objetivo de este trabajo fue hacer una revisión bibliográfica sobre la nocardiosis en perros y gatos, alertando al veterinario sobre la aparición de dicha afección.

Palabras clave: dermatología, enfermedades bacterianas, perros, gatos, nocardiosis, Nocardia spp.

\section{Introdução}

Dentre as doenças dermatológicas observadas no atendimento clínico de pequenos animais, as dermatopatias bacterianas são as mais frequentes (Cardoso et al., 2011; Larsson, 1996). Dentre estes microrganismos, os actinomicetos que fazem parte de um grupo complexo de bactérias composto por: Nocardia, Rhodococcus e Corynebacterium são os gêneros mais patogênicos para animais e humanos (Radostits et al., 2010). O gênero Nocardia consiste em bactérias aeróbicas, gram-positivas, parcialmente álcool-ácido resistentes, filamentosas e ramificadas (Beaman \& Beaman, 1994). Tal gênero é composto pelas seguintes espécies: Nocardia asteróides, $N$. farcinica, $N$. nova, $N$. brasiliensis, N. otitidiscaviarum e N. transvalensis (Corti \& Fioti, 2003). Essas bactérias são microrganismos ubíquos encontrados normalmente no solo, na água, em matéria orgânica em decomposição, poeira, vegetais e matéria fecal (Ettinger et al., 2017; Radostits et al., 2010; Sykes, 2015); porém, apesar dessa característica, esses microrganismos possuem a capacidade de manifestar mecanismos patogênicos, promovendo assim enfermidades (Golynski et al., 2006). A Nocardiose é uma infecção, causada por espécies da família Nocardiaceae (Corti \& Fioti, 2003) que acomete principalmente indivíduos imunocomprometidos (Sykes, 2015). Por essa razão, clínicos veterinários devem estar cientes do risco potencial de imunossupressão sistêmica e infecção subsequente com espécies de Nocardia (Condas et al., 2015; Hilligas et al., 2014; MacNeill et al., 2010). Classicamente, N. Asteroides é reconhecida como a espécie patogênica mais importante para o humano (Ackerman et al., 1982) e nocardiose animal em geral (Greene et al., 1993; Radostits et al., 2010). Nocardia asteroides, Nocardia brasiliensis, Nocardia farcinica e Nocardia novas ão as espécies mais comuns e patogênicas para animais de companhia (Greene et al., 1993; Scott et al., 1996).

Nos cães geralmente está associada à infecção pelo vírus da cinomose canina (Ribeiro et al., 2008) mas também pode estar associada ao uso prolongado de drogas imunosupressivas (Hilligas et al., 2014; MacNeill et al., 2010; Ribeiro et al., 2008) ou em pacientes portadores de hipotireoidismo, já que estes pacientes apresentam uma diminuição da taxa metabólica, contribuindo para a dificuldade de cicatrização das feridas (Leal et al., 2016; Scott-Moncrieff, 2007), sendo o gênero Nocardia spp. descrito como agente patogênico oportunista (Ribeiro et al., 2008). Leal et al. (2016) relatam um caso de dermatopatias piogranulomatosa por Nocardia spp. em paciente da espécie canina portador de hipotireoidismo. Acredita-se que outros fatores de risco para a ocorrência de nocardiose em cães estejam relacionados às falhas no manejo nutricional, de higienização e profilático desses animais, submetendoos a protocolos de vacinação inadequados, desverminação e sem efetivo controle de ectoparasitas (Frade et al., 2018). Olinda et al. (2011) relatam ainda um caso de um paciente canino que sofreu um acidente com objeto perfuro-cortante formando uma ferida penetrante na cavidade abdominal. A rota de infecção ocorre pela inalação de aerossóis, ingestão e contato com ambiente contaminado com o agente (Beaman \& Sugar, 1983; Kirpensteijn \& Fingland, 1992) ou pela inoculação percutânea por traumas (Edwards, 1998; Kirpensteijn \& Fingland, 1992; Sykes, 2015) causando as formas clínicas respiratórias e cutâneas, respectivamente (Edwards, 1998). As infecções nos animais são caracterizadas por lesões supurativas a granulomatosas com evolução crônica e de difícil resolução terapêutica (Beaman \& Beaman, 1994). Segundo Frade et al. (2018), em um estudo realizado por Ribeiro et al. (2008) ficou demonstrado que a espécie diagnosticada com mais frequência nas lesões cutâneas foi Nocardia otitidiscaviarum, sendo também encontrado um caso de Nocardia asteroides, e ainda, em um caso de lesão pulmonar foi isolado Nocardia nova. A correta identificação é importante para decidir o manejo clínico e o tratamento dos pacientes com a utilização de antibioticoterapia adequada (Marino \& Jaggy, 1993).

\section{Aspectos clínicos da doença}

Em animais de companhia as principais manifestações clínicas da nocardiose em sua forma cutânea são lesões tegumentares cutâneas ou subcutâneas que se desenvolvem até formarem abscessos crônicos 
localizados, com fístulas e úlceras necróticas que drenam uma secreção serossanguinolenta com aspecto de "sopa de tomate" (Kirpensteijn \& Fingland, 1992; Medleau et al., 2003; Ribeiro et al., 2008) podendo ainda se manifestar como lesões pulmonares (Kirpensteijn \& Fingland, 1992; Ribeiro et al., 2008). Em um estudo realizado por Frade et al. (2018) em quatorze cães com diagnóstico de nocardiose observouse predominantemente lesões no sistema respiratório, sendo comumente observado envolvimento do sistema nervoso central (SNC), observando-se ainda lesões cutâneas com disseminação sistêmica a partir dessas lesões primárias. As lesões cutâneas são mais frequentemente encontradas na região cervical e inguinal (Frade et al., 2018; Ribeiro et al., 2002) que podem apresentar-se na forma de abscessos, nódulos, úlceras e linfadenopatia (Condas et al., 2015; Hilligas et al., 2014). Além disso, pele, músculos, ossos e vasos linfáticos são locais comuns de infecção após a inoculação traumática (Beaman \& Beaman, 1994). As lesões atingem os membros ou abdômen e a linfadenomegalia periférica é comum (Medleau et al., 2003). Em felinos a forma cutânea é mais comum (Edwards, 1998). Na cavidade oral de cães promove doença periodontal, podendo, os microrganismos serem identificados na cavidade oral dos carnívoros. O trauma pela mordedura ou lambedura promove a inoculação destes, produzindo lesões piogranulomatosas, principalmente em pacientes imunossuprimidos (Fonseca et al., 2011; Fornazari et al., 2007; MacNeill et al., 2010). A presença de inapetência, emagrecimento e apatia são sinais comuns das afecções por Nocardia spp. nos cães e gatos (Edwards, 1998).

\section{Diagnóstico e diagnóstico diferencial}

A nocardiose deve ser considerada sempre em cães jovens que apresentam sinais respiratórios e neurológicos progressivos, assim como em lesões cutâneas com envolvimento do subcutâneo e linfonodos regionais (Frade et al., 2018). Processos supurativos piogranulomatosos com evolução crônica e refratários a tratamento convencional com antibióticos caracteriza infecções causadas por actinomicetos, incluindo Nocardia spp., devendo-se sempre examinar lesões cutâneas abscedidas em esfregaços corados pelo método de Gram (Golynski et al., 2006; Greene et al., 1993; Radostits et al., 2010).

A avaliação clínica do paciente deve incluir anamnese e exame físico completo, com realização de exames laboratoriais para detecção de doença sistêmica predisponente, infecção sistêmica concomitante ou imunossupressão (Olinda et al., 2011). O diagnóstico da nocardiose pode ser feito através do histórico, exames hematológicos, sinais clínicos, além de exames microbiológicos e moleculares pela análise de enzimas de restrição e da PCR, permitindo a caracterização das espécies patogênicas atualmente conhecidas; porém, a ocorrência de doenças associadas e sinais clínicos inespecíficos podem mascarar e dificultar o diagnóstico (Brown-Elliott et al., 2006; Malik et al., 2006; Marino \& Jaggy, 1993; Ribeiro et al., 2002). Na avaliação hematológica desses pacientes normalmente é observado leucocitose caracterizada por neutrofilia com desvio à esquerda (Golynski et al., 2006; Olinda et al., 2011). Na prática clínica, o diagnóstico primário é realizado através do exame citológico a partir do exsudado da lesão corada pelo Gram, no qual é possível observar bactérias cocóides gram-positivas filamentosas, que se apresentam parcialmente ácido-resistentes (Golynski et al., 2006). Golynski et al. (2006) relatam um caso de nocardiose em cão, no qual realizou-se o exame citológico através da punção por agulha fina, no qual foram colhidas amostras do nódulo cutâneo que o mesmo apresentava. $\mathrm{O}$ autor ainda relata que a coloração da amostra pode ser realizada do método Diff-Quick ou pela metodologia segundo Romanowsky.

No exame foi observado, além de bactérias filamentosas e ramificado, numerosos neutrófilos e macrófagos (Figura 1).

Segundo Greene et al. (1993), o diagnóstico definitivo é feito por meio de cultura bacteriana em meio aeróbico ou enriquecido com dióxido de carbono. Segundo Leck (2015), Leal et al. (2016) e Frade et al. (2018) nos casos em que o aspecto macroscópico da lesão dificulte o diagnóstico e a coleta de material para cultivo e isolamento, o exame histopatológico realizada pela técnica de coloração através do ácido periódico de Schiff (PAS) demonstrou ser uma ferramenta importante para o diagnóstico. Ainda podese utilizar o diagnóstico sorológico em cães naturalmente infectados (Fawi, 1964). 


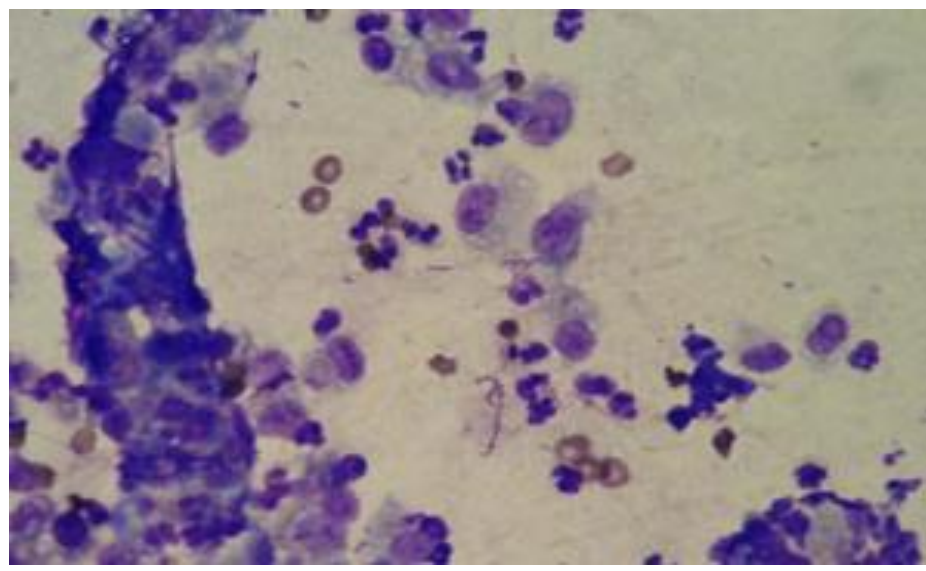

Figura 1. Numerosos netutrófilos e macrófagos. Bactérias cocóides filamentosas ramificadas (Diff-quick, x1000) Fonte: Golynski et al. (2006).

Morfologicamente Nocardia e Actinomyces são semelhantes; porém, em colorações especiais o segundo é impregnado pela prata (GMS) e Gram positivo não sendo, porém, álcool-ácido resistente (Condas et al., 2015; Sykes, 2015). Devem-se considerar ainda no diagnóstico diferencial outros gêneros de actinomicetos, como Mycobacterium, porém essas bactérias são observadas como bacilos não corados pelo Giemsa, sendo também álcool-ácido resistentes (Raskin \& Meyer, 2003). A Nocardia pode ser confundida com fungos pela semelhança no diagnóstico, através da citologia utilizada ou conforme a morfologia de crescimento colonial (MacNeill et al., 2010).

\section{Tratamento}

O Tratamento com antibioticoterapia é recomendado, levando sempre em consideração a gravidade, a localização anatômica da infecção e a imunidade do hospedeiro (Corti \& Fioti, 2003). As combinações de trimetoprim-sulfonamidas, cefalosporinas, amicacina, ampicilina, imipenem, minociclina e linezolida são medicamentos recomendados para tratamento nocardial que envolve o curso prolongado antimicrobiano, por semanas a meses, mantendo a medicação durante, no mínimo, quatro semanas após a cura clínica completa, combinado com terapia de apoio e cirurgia (Greene et al., 1993; Medleau et al., 2003; Radostits et al., 2010). No entanto, a escolha do antiobiótico, sempre que possível, deve se basear em resultados de cultura e antibiograma (Medleau et al., 2003).

Em casos em que haja recorrência ou resposta terapêutica insuficiente é recomendado que se realizasse o debridamento cirúrgico das áreas lesionadas por esse processo patológico (Ribeiro et al., 2008). Segundo Baldi et al. (2006) e Condas et al. (2015) o tratamento da nocardiose cutânea mais eficiente se dá através da combinação de remoção cirúrgica dos tecidos infectados e tratamento com antibióticos sensíveis testados através da cultura com antibiograma de forma prolongada, superior ao tratamento apenas com antibioticoterapia.

\section{Prognóstico}

O diagnóstico e o tratamento precoces são essenciais para o prognóstico favorável da nocardiose (Olinda et al., 2011), sendo este considerado incerto em infecções disseminadas em animais de companhia (Greene et al., 1993; Radostits et al., 2010). Segundo Condas et al. (2015) o prognóstico em animais com condições imunossupressoras associadas é desfavorável, não existindo medidas específicas para o controle e profilaxia da nocardiose, devido à ampla distribuição do microrganismo no ambiente.

\section{Considerações finais}

É de grande importância o estudo do gênero Nocardia e a compreensão dos aspectos patológicos e epidemiológico da nocardiose, visto que tais bactérias são amplamente encontradas no ambiente. A nocardiose ainda é considerada uma doença incomum em cães e gatos. Sempre que o clínico veterinário de pequenos animais se deparar com pacientes que apresentem feridas, úlceras ou abscessos não responsivos a tratamento com antibioticoterapia deve-se realizar exames para descartar a possibilidade de infecção por Nocardia spp. O diagnóstico precoce, o tratamento inicial apropriado e o controle de fatores 
concomitantes influenciam diretamente no prognóstico da doença, diminuindo a taxa de mortalidade dos pacientes acometidos.

\section{Referências bibliográficas}

Ackerman, N., Grain Júnior, E. \& Castleman, W. (1982). Canine nocardiosis. Journal of the American Animal Hospital Association, 18(1):147-153.

Baldi, B. G., Santana, A. N. C. \& Takagaki, T. Y. (2006). Pulmonary and cutaneous nocardiosis in a patient treated with corticosteroids. Jornal Brasileiro de Pneumologia, 32(6):592-595.

Beaman, B. L. \& Beaman, L. (1994). Nocardia species: host-parasite relationships. Clinical Microbiology Reviews, 7(2):213-264.

Beaman, B. L. \& Sugar, A. M. (1983). Nocardia in naturally acquired and experimental infections in animals. Epidemiology \& Infection, 91(3):393-419.

Brown-Elliott, B. A., Brown, J. M., Conville, P. S. \& Wallace, R. J. (2006). Clinical and laboratory features of the Nocardia spp. based on current molecular taxonomy. Clinical Microbiology Reviews, 19(2):259-282.

Cardoso, M. J. L., Machado, L. H. A., Melussi, M., Zamarian, T. P., Carnielli, C. M. \& Júnior Ferreira, J. C. M. (2011). Dermatopatias em cães: revisão de 257 casos. Archives of Veterinary Science, 16(2):66-74

Condas, L. A. Z., Ribeiro, M. G., Muro, M. D., Vargas, A. P. C., Matsuzawa, T., Yazawa, K., .. Risseti, R. M. (2015). Molecular Identification and antimicrobial resistance pattern of seven clinical isolates of Nocardia spp. in Brazil. Revista do Instituto de Medicina Tropical de São Paulo, 57(3):251-256.

Corti, M. E. \& Fioti, M. E. V. (2003). Nocardiosis: a review. International Journal of Infectious Diseases, 7(4):243-250.

Edwards, D. F. (1998). Actinomycosis and nocardiosis. In C. E. Greene (Ed.), Infectious diseases of the dog and cat. Philadelphia, USA: WB Saunders Co.

Ettinger, S. J., Feldman, E. C. \& Cote, E. (2017). Textbook of Veterinary Internal Medicine-eBook. USA: Elsevier Health Sciences.

Fawi, M. (1964). Complement fixing antibodies in nocardiosis with special reference to dogs. Sabouraudia, 3(4):303-305.

Fonseca, S. A., Galera, P. D., Brito, D. L., Silva, A. S., Cardoso, L. B., Marçola, T. G. \& Perecmanis, S. (2011). Análise microbiológica da placa bacteriana da doença periodontal em cães e o efeito da antibioticoterapia sobre ela. Ciência Rural, 411424-1429.

Fornazari, F., Ribeiro, M. G., Santos, F. C., Teixeira, C. R., Rahal, S. C., Teixeira, R. H. F. \& Rassy, F. B. (2007). Microbiota oral e sensibilidade microbiana in vitro em oito quatis criados no zoológico municipal Quinzinho de Barros, Sorocaba, SP. Ciencia Veteterinária nos Trópicos, 10(2/3):108-112.

Frade, M. T. S., Firmino, M. O., Maia, L. A., Silveira, A. M., Nascimento, M. J. R., Martins, F. S. M., . .. Dantas, A. F. M. (2018). Características epidemiológicas, clínico-patológicas e morfotintoriais de quatorze casos de nocardiose em cães. Pesquisa Veterinária Brasileira, 38(1):99-106.

Golynski, M., Szczepanik, M., Pomorska, D. \& Wilkolek, P. (2006). Cutaneous nocardiosis in a dogclinical case presentation. Bull Vet Inst Pulawy, 5047-50.

Greene, C. E., Samperio, J. O. \& Gómez, J. P. (1993). Enfermedades infecciosas: Perros y gatos. São Paulo: Editora Interamericana.

Hilligas, J., Van Wie, E., Barr, J., Russell, K. E., Perry, A. L., Weeks, B. R. \& Zhang, S. (2014). Vertebral osteomyelitis and multiple cutaneous lesions in a dog caused by Nocardia pseudobrasiliensis. Journal of Veterinary Internal Medicine, 28(5):1621-1625.

Kirpensteijn, J. \& Fingland, R. B. (1992). Cutaneous actinomycosis and nocardiosis in dogs: 48 cases (1980-1990). Journal of the American Veterinary Medical Association, 201(6):917-920.

Larsson, C. E. (1996). Dermatopatias alérgicas-hipersensibilidade medicamentosa (HM). Clínica Veterinária, 5(1):351-355. 
Leal, P. D. S. A., Almeida, E. C. P. A. \& Lopes, C. W. G. (2016). Diagnóstico de dermatopatia piogranulomatosa por Nocardia spp. numa cadela Labrador Retriever com hipotireoidismo, Rio de Janeiro, Brasil-Relato de caso. Brazilian Journal of Veterinary Medicine, 38(2):203-209.

Leck, A. (2015). Taking a corneal scrape and making a diagnosis. Community eye health, 28(89):8.

MacNeill, A. L., Steeil, J. C., Dossin, O., Hoien-Dalen, P. S. \& Maddox, C. W. (2010). Disseminated nocardiosis caused by Nocardia abscessus in a dog. Veterinary Clinical Pathology, 39(3):381-385.

Malik, R., Krockenberger, M. B., O’BRIEN, C. R., White, J. D., Foster, D., Tisdall, P. L. C. \& McCowan, C. (2006). Nocardia infections in cats: a retrospective multi-institutional study of 17 cases. Australian Veterinary Journal, 84(7):235-245.

Marino, D. J. \& Jaggy, A. (1993). Nocardiosis: a literature review with selected case reports in two dogs. Journal of Veterinary Internal Medicine, 7(1):4-11.

Medleau, L., Hnilica, K. A. \& Fagliari, G. S. (2003). Dermatologia de pequenos animais: atlas colorido e guia terapêutico. São Paulo: Roca.

Olinda, R. G., Reis, P. F. C. C., Loreno, K., Tomaz, R., Bezerra, F. S. B., Alves, N. D. \& Feijó, F. M. C. (2011). Nocardiose cutânea em cão. Revista Centauro, 2(1):18-22.

Radostits, O. M., Gay, C. C., Blood, D. C., Hinchcliff, K. W. \& McKenzie, R. A. (2010). Clínica Veterinária: um tratado de doenças dos bovinos, ovinos, suínos, caprinos e eqüinos (Vol. 1). Rio de Janeiro: Guanabara Koogan.

Raskin, R. E. \& Meyer, D. J. C. (2003). Atlas de citologia de cães e gatos. São Paulo, Brasil: Roca.

Ribeiro, M. G., Aguiar, D. D., Paes, A., Megid, J., Giuffrida, R., Nardi Junior, G. D. \& Ueno, T. (2002). Nocardiose cutânea associada à cinomose em cães. Relato de dez casos. Revista Clínica Veterinária, 3934-42.

Ribeiro, M. G., Salerno, T., Mattos-Guaraldi, A. L., Camello, T. C. F., Langoni, H., Siqueira, A. K. \& Lara, G. H. B. (2008). Nocardiosis: an overview and additional report of 28 cases in cattle and dogs. Revista do Instituto de Medicina Tropical de São Paulo, 50(3):177-185.

Scott-Moncrieff, J. C. (2007). Clinical signs and concurrent diseases of hypothyroidism in dogs and cats. Veterinary Clinics of North America: Small Animal Practice, 37(4):709-722.

Scott, D. W., Muller, G. H. \& Kirk, R. W. (1996). Dermatologia dos pequenos animais (Vol. 1). Rio de Janeiro: Interlivros.

Sykes, J. E. (2015). Actinomicose e Nocardiose. In C. E. Greene (Ed.), Doenças infecciosas em cães e gatos. Rio de Janeiro, Brasil: Guanabara Koogan.

Recebido: 31 de outubro, 2019

Aprovado: 29 de novembro, 2019.

Publicado: 16 de janeiro, 2020

Licenciamento: Este artigo é publicado na modalidade Acesso Aberto sob a licença Creative Commons Atribuição 4.0 (CC-BY 4.0), a qual permite uso irrestrito, distribuição, reprodução em qualquer meio, desde que o autor e a fonte sejam devidamente creditados. 